The Laboratory of the Government Chemist is very often involved in legal cases arising out of such illegalities as the dilution of beer, illicit distilling and forgery. The present report gives some excellent illustrations on the methods used to detect forgeries.

Although mainly concerned with the utilization of existing analytical methods, the Laboratory carries out a considerable amount of research work on the improvement of analytical methods and their adaptation to meet problems peculiar to the types of sample received for analysis. The report also indicates that the small but increasing research programme on the development of new methods of analy- sis is meeting with considerable success. The new radiochemical section has begun work for municipal water supplies, and on the analysis of effluents from atomic energy establishments.

This report shows admirably that as a means for safeguarding the public interest over a wide field of activity, the Laboratory is second to none. This report has been read with considerable interest not only for its scientific content but also for the extreme diversity of its contents. The new Government Chemist, Dr. D. T. Lewis, is to be congratulated on the presentation of this, his first report.

William I. Stephen

\title{
AMSTERDAM CONFERENCE ON PARTICLE ACCELERATORS
}

\begin{abstract}
7 HE January number of Nuclear Instruments and Methods* is devoted entirely to the proceedings of the Second Accelerator Conference which was held in Amsterdam during October 4-6, 1960. The Conference, which was sponsored by the High Voltage Engineering Corporation, Burlington, Massachusetts, and High Voltage Engineering (Europa) N. V., Amersfoort, The Netherlands, consisted of four sessions, under the chairmanship of Profs. H. Brinkman (University of Groningen), H. H. Staub (University of Zurich), K. Siegbahn (University of Uppsala) and A. Charlesby (Royal Military College of Science), respectively. The seven papers in the first session were devoted to nuclear physics, and dealt with resonance reactions, the generation of positrons in a thick target, desirable linear electron accelerator characteristics for nuclear research, Coulomb excitation, experiments using ultra-fast pulse techniques, nuclear widths and life-times, and colliding beam techniques. Three of the six papers in the session on particle research discussed tandem accelerators. P. H. Rose of the High Voltage Engineering Corporation described two forms of the three-stage tandem accelerator, one with negative ion injection and the other with neutral beam injection. H. E. Gove of the Atomic Energy of Canada, Ltd., gave an account of the tandem accelerator installation at Chalk River and of two particular fields of investigation during 1960. The Chalk River accelerator began operating in February 1959 and has operated continuously on a two-shift a day, five-day week basis since then. The

* Nuclear Instruments and Methods, 11, No. 1: Proceedings of the Second Accelerator Conference, Amsterdam, October 4-6, 1960. Edited by $\mathrm{K}$. Siegbahn. Pp. xil + 256. (Amsterdam: North-Holland Publishing Company). 908 .
\end{abstract}

first investigation was concerned with the interaction between beams of heavy ions such as carbon-12, nitrogen-14 and oxygen-16, with targets of nitrogen, oxygen, fluorine, neon, magnesium, aluminium and silicon, and the second with measurements of spins of levels in even-even nuclei lying between oxygen-16 and calcium-40. Recent research work carried out at the Atomic Weapons Research Establishment, Aldermaston, on nuclear reactions using a tandem accelerator and $6 \cdot \mathrm{MeV}$. electrostatic generators $w$ as described by K. W. Allen. Oxygen ions accelerated in the accelerator to energies of $10-40 \mathrm{MeV}$. were used for Coulomb excitation of energy-levels in both rotational and vibrational nuclei and for the measurement of nuclear life-times by Doppler-shift methods. The final paper in the nuclear physics session was given by J. C. Nygard and R. F. Post on recent advances in high-power micro-wave electron accelerators for physics research.

The third and final sessions were devoted to physics and radiation research. The subjects covered included the use of Van de Graaff accelerators, pulsed neutron sources and ion sources. In the industrial applications section, the use of the electron accelerator in solid-state physics, and of high-energy radiation in biochemical and microbiological research were discussed by P. Baruch, and S. T. H. Pinner and W. T. H. Davison, respectively. The report of the proceedings concludes with a most impressive and long list of accelerators (Van de Graaff, micro-wave linear electron and Cockcroft-Walton) which have been installed in various centres all over the world by the High Voltage Engineering Corporation, and associated companies.

\section{CONTINENTAL AND OCEANIC DIFFERENTIATION}

$\mathrm{D}^{\mathrm{n}}$ R. ROBERT DIETZ'S recent article ${ }^{1}$ is a marked contribution to what might be called the oceanographic revolution in geotectonics. One gets the impression that with it a stage has been reached like the last but one in fitting together a jigsaw puzzle, with the various parts of the puzzle having been laboriously assembled, piece by piece, at last seeming to look as if they are all part of one single picture.

What Dr. Dietz has done, effectively, is to combine the notions derived from the recent discovery of oceanographers of mid-oceanic rift ridges and transcurrent faults, with the older pictures, derived from earthquake and gravity measurements, of the pushing up of continental edges along conical thrust faults exposing themselves as mountain ranges, island-arcs and trench systems, according to the ideas of Meinesz and van Bemmelen, and set out specially by Tuzo Wilson. The leading new idea, linked with the still hypothetical mantle convexion systems, is one of expanding oceanic floors, split vertically by latitudinal and circumoceanic transcurrent faults, passing under the continents. This removes many difficulties and makes it possible to envisage a mantle which can expand under some parts of the crust and contract under others at the same time. 